\title{
Orthodontic treatment of severe crowding malocclusion with temporomandibular joint closed-lock by means of multi-loop edgewise archwire: a case report
}

\author{
T. Kawagoe, S. Akimoto, S. Sato \\ Division of Orthodontics, Department of Craniofacial Growth and Development Dentistry, \\ Kanagawa Dental College, Yokosuka, Kanagawa, Japan
}

Received November 7, 2009; Accepted January 12, 2010

In this case report, crowding malocclusion with TMJ (temporomandibular joint) closed lock was treated with modified offset archwire (MOAW) and multi-loop edgewise archwire (MEAW). Owing to the TMD (temporomandibular disorder) problems, we decided to extract the lower third and upper second molars. Crowding in the upper and lower arches was successfully treated with the improvement of TMD. Condylar movement was improved by orthodontic treatment with $\Delta \mathrm{Y}$ shift noted on condylographic evaluation. Two years after the treatment, the occlusion was fairly stable.

Keywords: TMD, malocclusion, closed lock, MOAW, MEAW

\section{Introduction}

In recent years, the number of patients with temporomandibular disorder (TMD) has increased. Treatment approaches including splint therapy, pumping manipulation, arthrocentesis, and arthroscopic surgery have been applied in the last three decades to relieve the symptoms of TMD. Occlusal splints have been reported to lead to functionally satisfactory results in the cases of TMD $[3,16,21]$, indicating that occlusion is one of the causative factors of TMD. Kurita et al. [9] reported that successful reduction of the disk by mandibular manipulation is rare. Some researchers reported that arthroscopic surgery was effective to decrease temporomandibular joint (TMJ) pain [5, 10]. Ohnuki et al. [11] reported that clinical signs and symptoms were alleviated by treatment such as splint therapy, arthrocentesis, arthroscopic surgery, and pumping manipulation but that these do not necessarily improve the position and deformity of the disk. However, disk mobility is important for improving TMD symptoms.

Rusanen et al. [15] reported that there were few changes in the number of TMJ with joint effusion after treatment and that the significant decrease in signs and symptoms of TMD after extensive surgical/orthodontic or orthodontic treatment is likely a consequence of better

Correspondence: Susumu Akimoto, 82 Inaoka-cho, Yokosuka City, Kanagawa, Japan. E-mail: akimoto5895s@kdcnet.ac.jp occlusal function, which in turn is related to favorable changes in muscular balance. Results from different modalities of TMD treatment indicate that recovering the harmony between the motility of TMJ and support by occlusion is more important for providing long-lasting function of the masticatory organ than we expected before. Therefore, the trend of TMD treatment has been shifting slowly but definitely; currently, achieving better occlusal function is the first aim of the TMD treatment.

One of the most frustrating symptoms of TMD for the patient is disk dislocation without reduction (closed lock), in which the joint does not allow complete translation of its condyle. It has been pointed out that some occlusal conditions affect TMD because of orthopedic instability. When the teeth are not correctly aligned in occlusion and when orthopedic instability exists, the mandibular position is displaced because of poor occlusal support; hence, the condyle is concomitantly displaced and compressed followed by disk dislocation. Treating patients with these symptoms, making the correct diagnosis, offering a favorable occlusion, and providing stable support are extremely important for a definitive approach.

Many different approaches were reported to treat closedlock TMD patients; however, a few described the approach from the aspect of occlusion, including mandibular reposition and relationship between occlusal status and condylar position. Our department has been using a mandibular tracking device (Cadiax system) to diagnose malocclusion in patients with TMD $[17,18]$. On the basis of the functional information, malocclusion patients with TMD symptoms have been treated successfully using mechanics which provide stable occlusal support by uprighting buccal segments and avoiding premolar extraction.

The purpose of this case report is to describe our treatment approach to a patient with closed-lock TMJ.

\section{Diagnosis and etiology}

A 13-year-old girl had been referred to the Department of Orthodontics with the chief complaint of crowding in the 

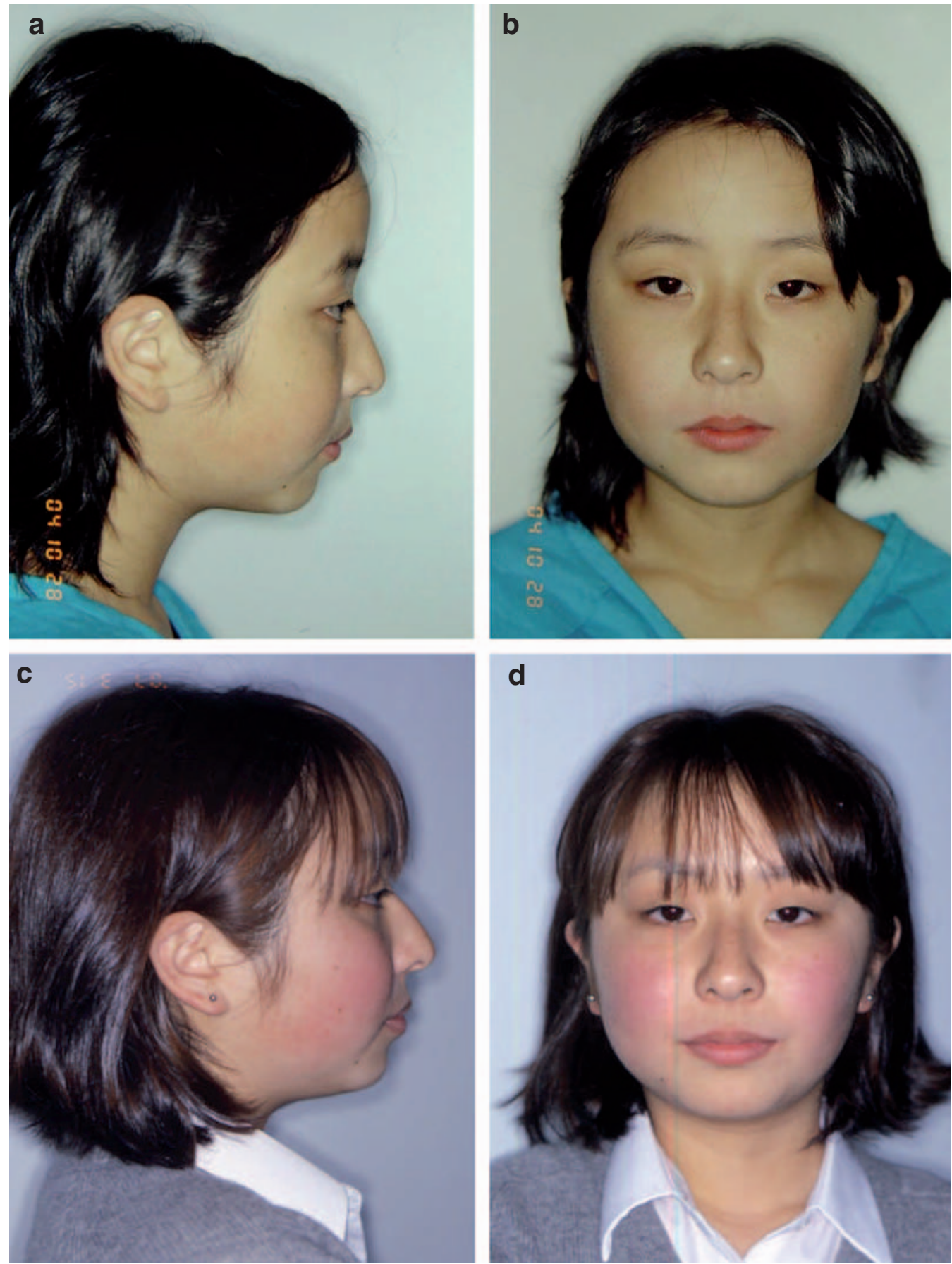

Fig. 1: Pre- and post-treatment facial photographs. (a and b) Pre-treatment, (c and d) post-treatment

upper and lower arches and difficulty to open her mouth widely. Her medical history indicated problems due to mouthbreathing and TMD symptoms. She had no pain on her TMJ, but could not open her mouth widely.

The patient had a convex-type facial profile. In the frontal view of a facial photograph, her mandible deviated slightly to the left (Fig. 1). In a P-A cephalogram, her mandible also deviated to the same side when facial asymmetry was evaluated using the mid-facial reference plane (Crysta gali to ANS) and lower facial mid line (anterior nasal spine to menton line, ANS-Me). Occlusal analysis showed a Class I molar relation- ship on both sides, crowding of upper and lower arches, high canines in the upper arch, an overbite of $1.5 \mathrm{~mm}$, and an overbite of $3 \mathrm{~mm}$ (Fig. 2). Panoramic radiographs revealed impacted upper and lower third molars and mesially inclined lower molars (Fig. 3). Cephalometric evaluation showed a skeletal Class II relationship (SNA 78, SNB 72). The inclinations of the upper and lower incisors were average (U-1 to FH 109) (Fig. 4).

We used condylography to characterize condylar movements (Cadiax ${ }^{\circledR}$, Gamma Corp., Kosterneuburg, Austria). Condylography enhances the tracking of hinge-axis movements 

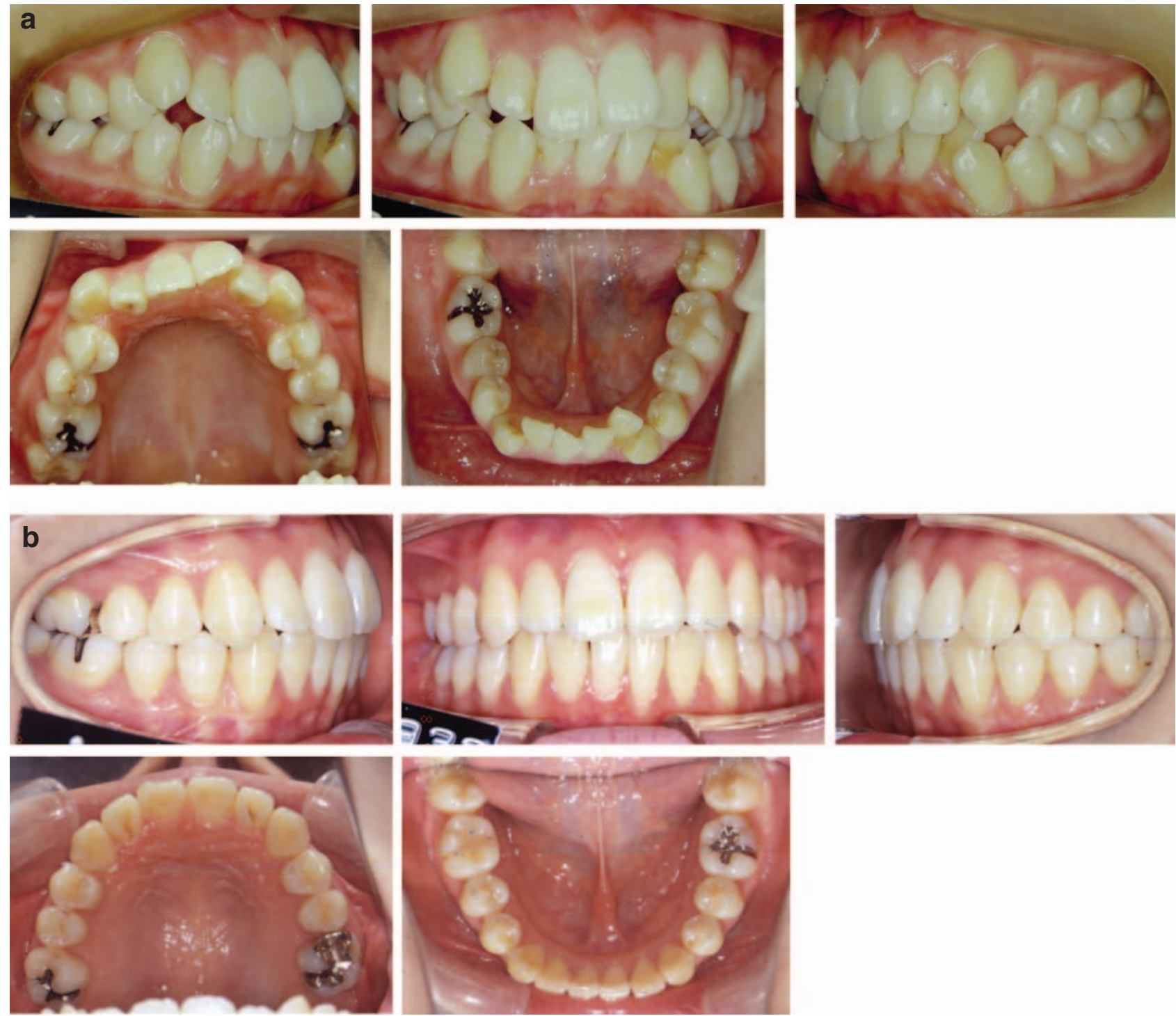

Fig. 2: Pre- and post-treatment intra-oral photographs. (a) Pre-treatment, (b) post-treatment
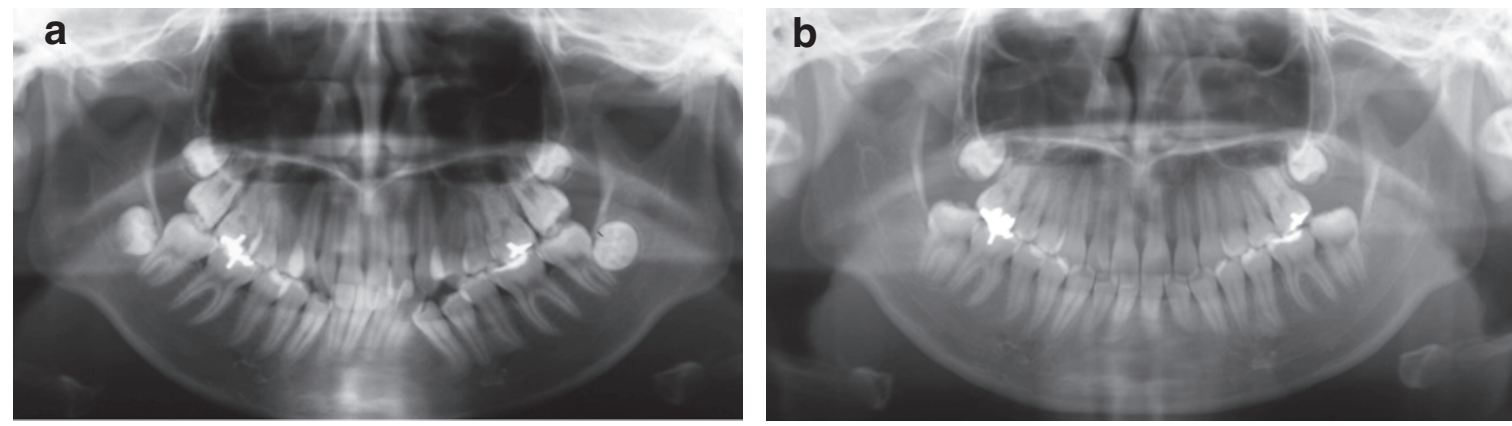

Fig. 3: Pre- and post-treatment panoramic radiographs. (a) Pre-treatment, (b) post-treatment

in horizontal $(\mathrm{X})$, vertical $(\mathrm{Z})$, and transverse $(\mathrm{Y})$ dimensions with a computer program $[17,18]$. We recorded different mandibular movements, protrusion/retrusion, right/left mediotru- sion, open/close, mastication, swallowing, bruxism, and phonation movements and measured the RP-ICP difference with a mandibular-position indicator (EMPI).

Orthodontic treatment of severe crowding malocclusion 

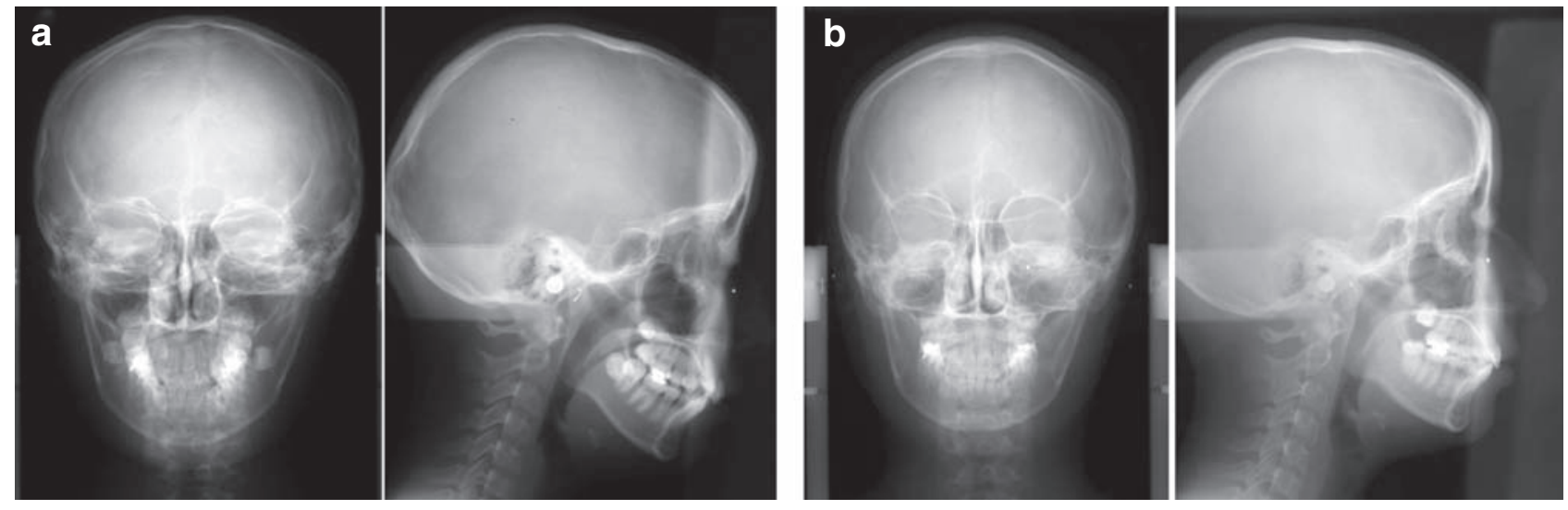

Fig. 4: Pre- and post-treatment cephalograms. (a) Pre-treatment, (b) post-treatment

a

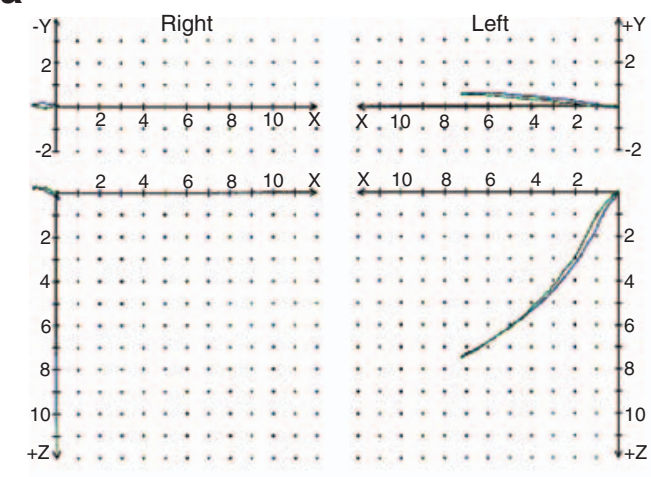

C

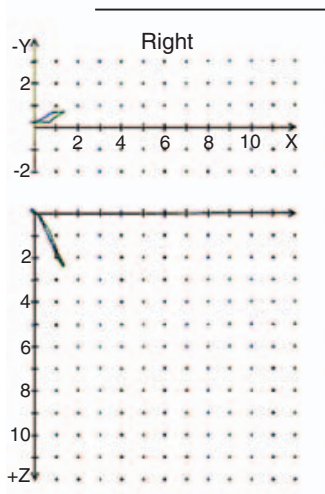

e-r.

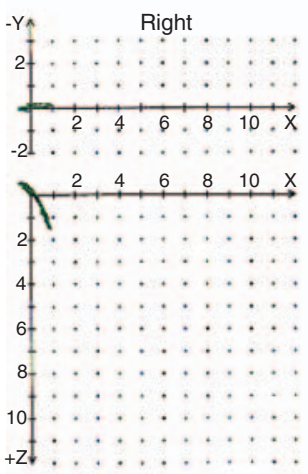

b

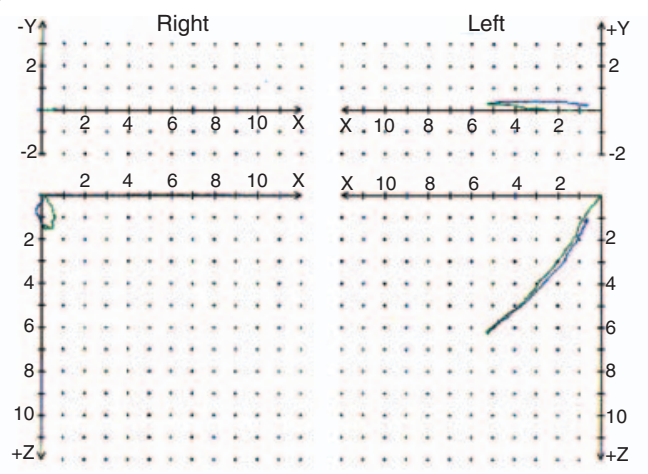

$\mathbf{d}_{-}$
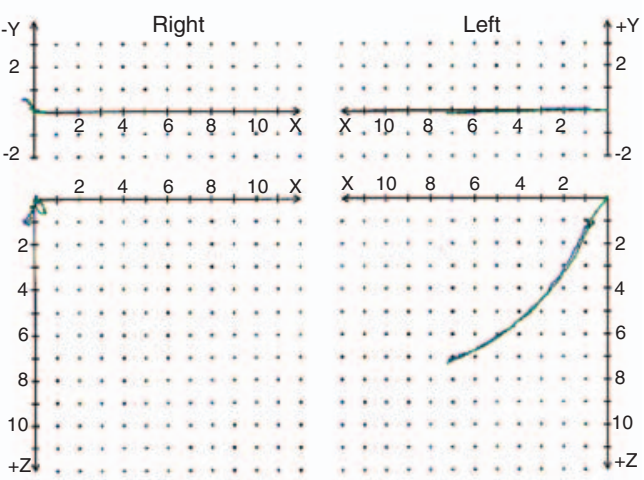

f

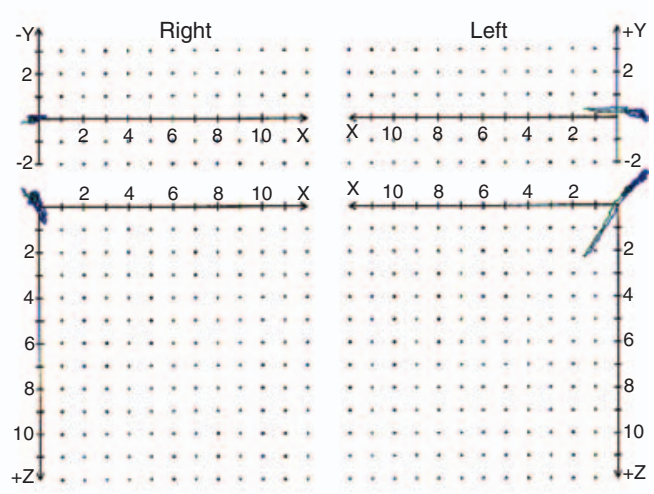

Fig. 5: Condylar movements recorded by condylography in pre-treatment. (a) Protrusion/retrusion, (b) open/close, (c) mediotrusion/right, (d) mediotrusion/left, (e) bruxism movement, (f) mastication 
a

$\begin{array}{lr}\text { RP }->\text { ICP } \\ \text { dXR } & -0.19 \\ \text { dZR } & -0.44 \\ \text { dXL } & -0.09 \\ \text { dZL } & -0.39 \\ \text { dY } & -0.01 \\ \text { dH } & 9.49 \\ \text { dW } & -0.15 \\ \text { dL } & -7.40 \\ \text { Gamma } & 4.17\end{array}$

RP $>$ FBP

$\begin{array}{ll}\text { dXR } & -0.40\end{array}$

dZR $\quad-0.36$

$\begin{array}{ll}d X L & -0.29\end{array}$

dZL $\quad-0.40$

$\begin{array}{ll}\text { dY } & 0.00\end{array}$

$\mathrm{dH} \quad 7.77$

$\mathrm{dW} \quad-0.11$

dL $\quad-6.25$

Gamma 3.42
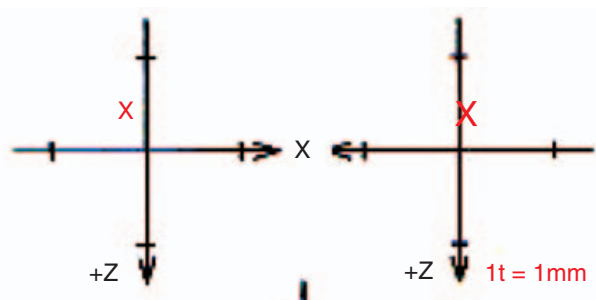

$+$
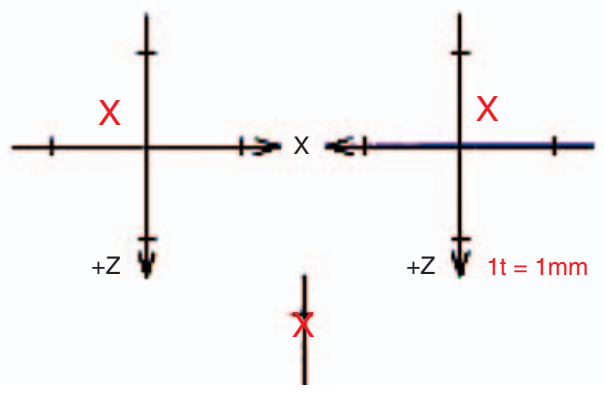

$\frac{1}{1}$

$+Z \sqrt{1 \mathrm{t}=1 \mathrm{~mm}}$ b
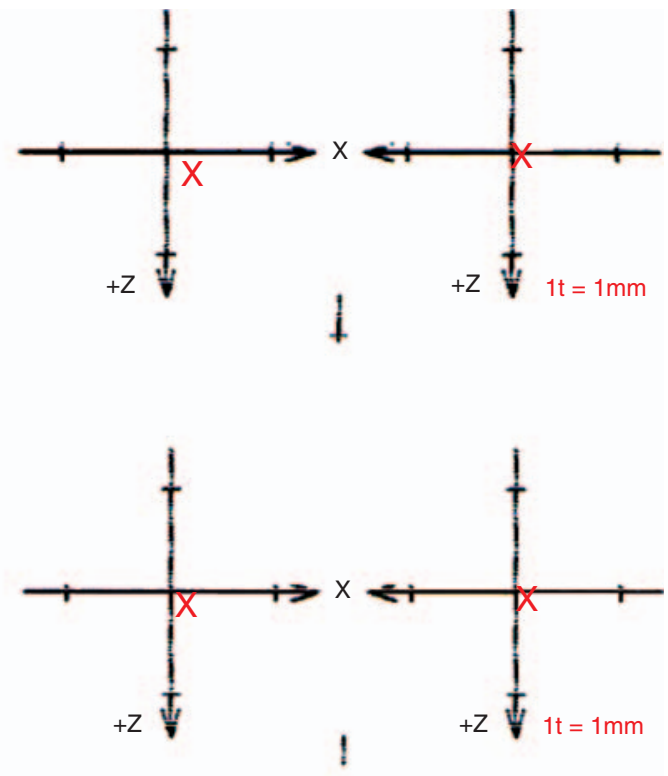

Fig. 6: Evaluation of occlusal support by condylography in pre- and post-treatment. (a) Pre-treatment, (b) post-treatment. Difference of condylar position in RP-ICP and RP-Clench showed strong compression pre-treatment, which indicated poor occlusal support, but post-treatment showed no compression
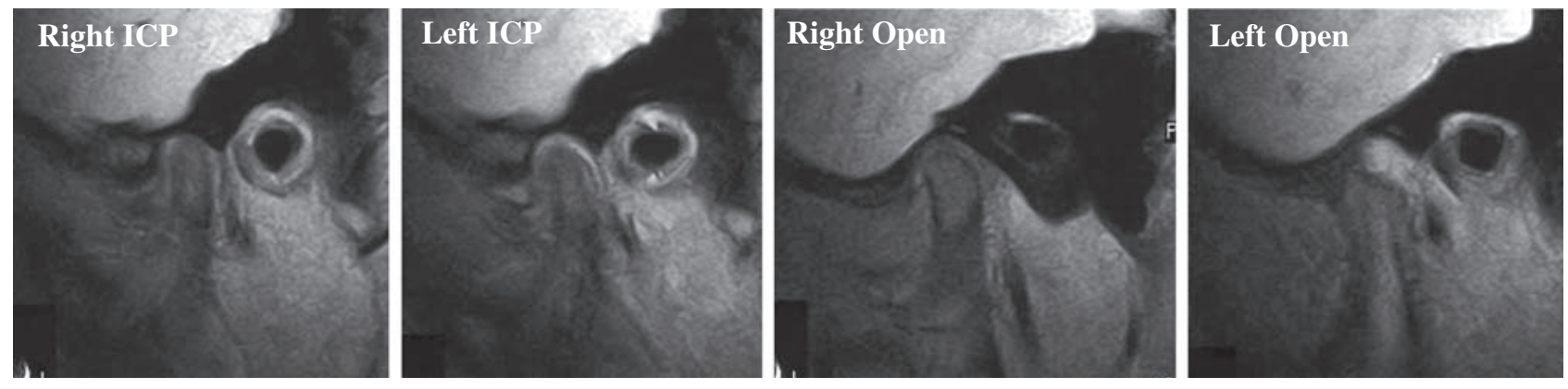

Fig. 7: MRI examination before treatment. Right TMJ showed anterior disk displacement without reduction, while left-side TMJ showed anterior disk displacement with reduction
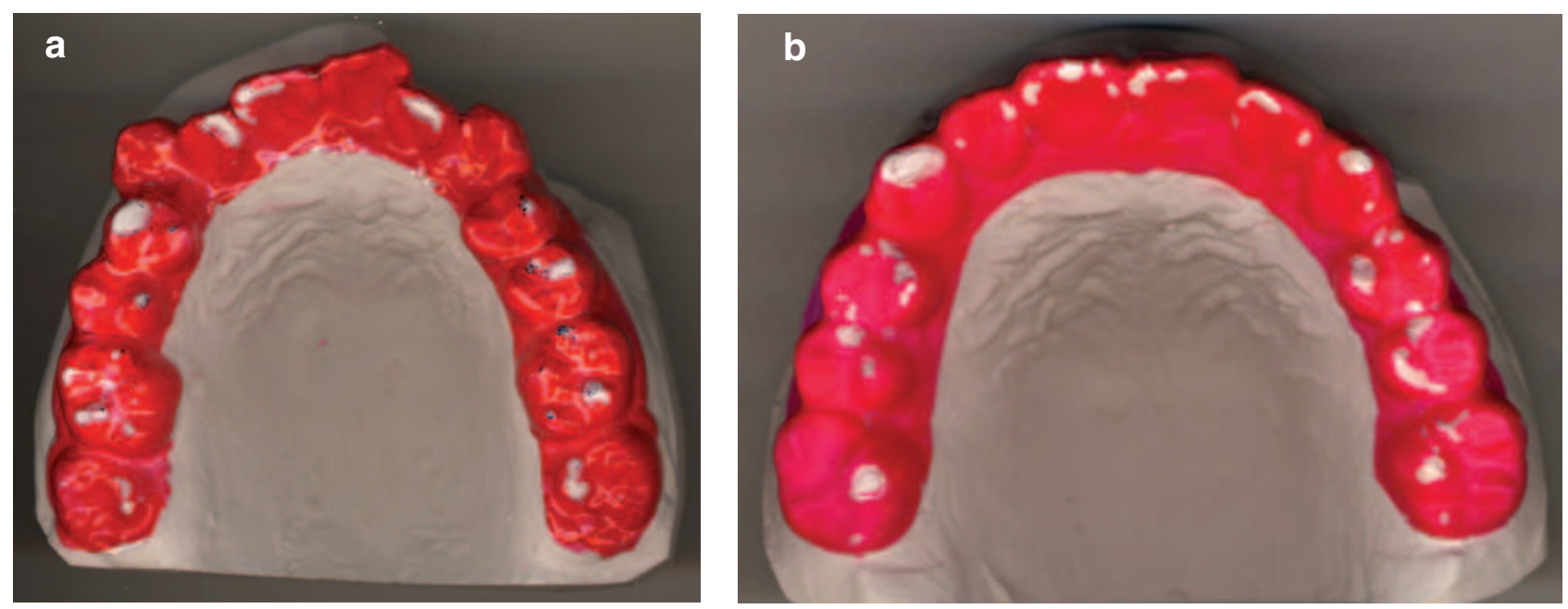

Fig. 8: Tooth contact pattern during sleep bruxism evaluated using Bruxchecker. Pre-treatment (a) showed no canine dominance tooth contact, but post-treatment bruxchecker (b) showed canine guided tooth contact 

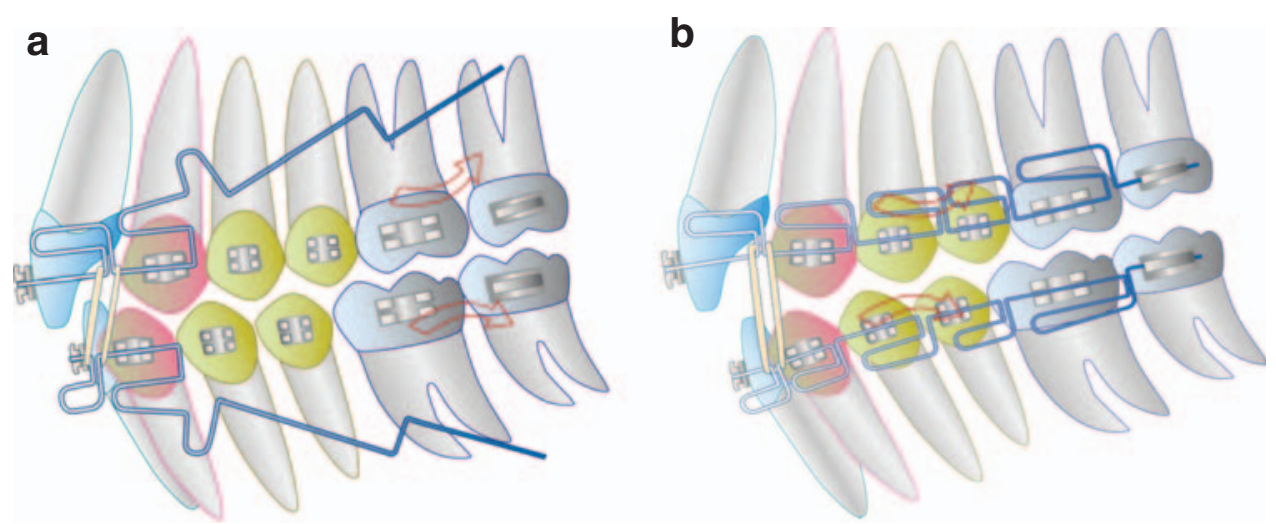

Fig. 9: Treatment mechanics used in orthodontic correction. (a) Modified offset archwire (MOAW) with anterior vertical elastics was used to upright molars in the first step. (b) Multiloop edgewise arch wire (MEAW) was applied with anterior vertical elastics to upright buccal segments in the second step
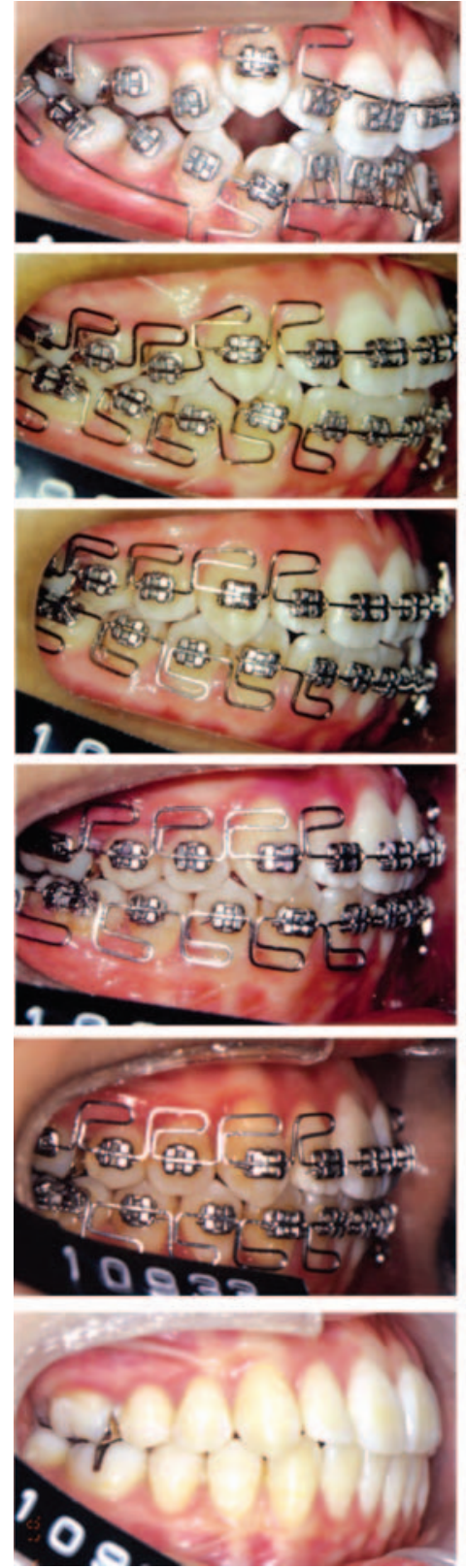
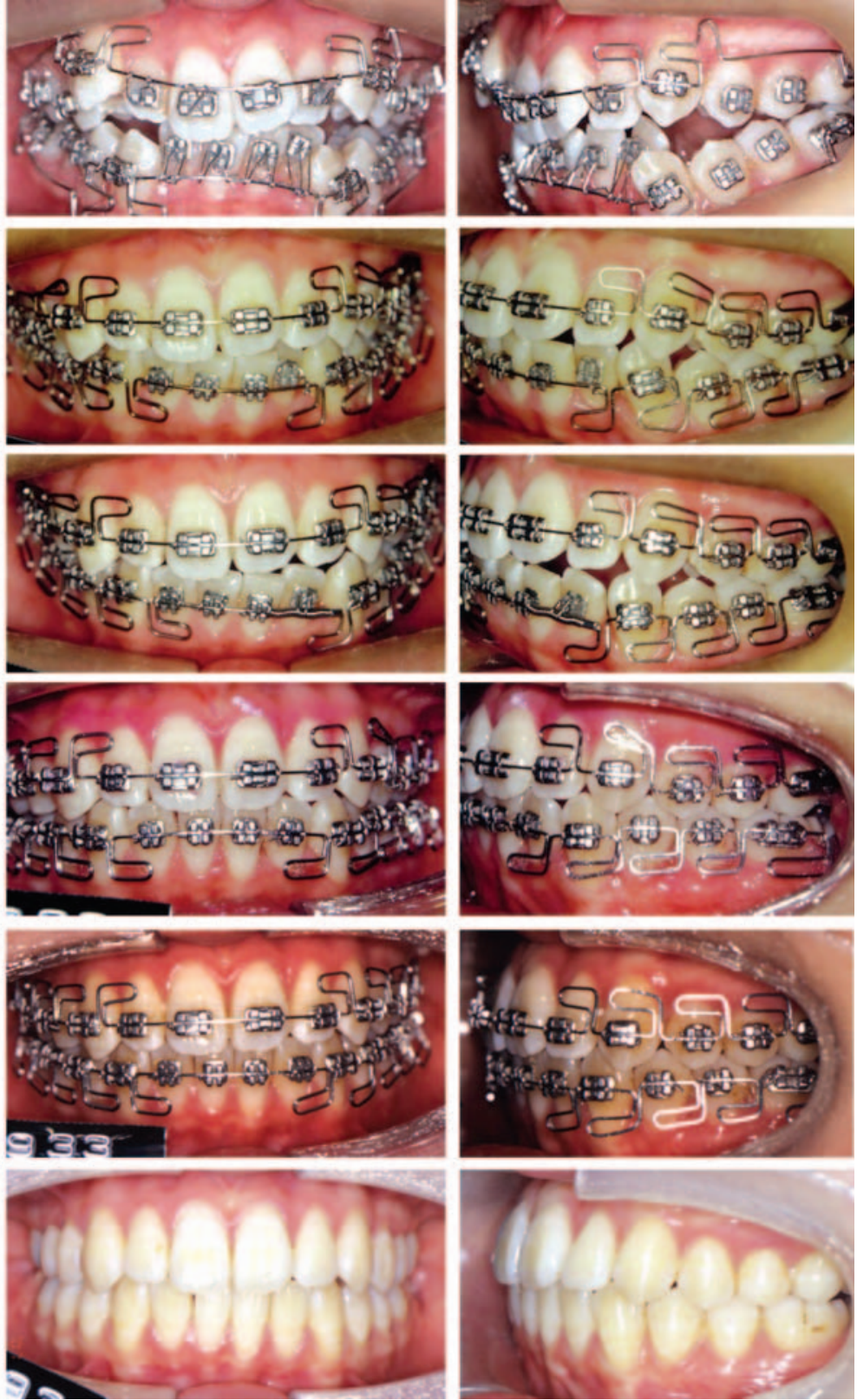
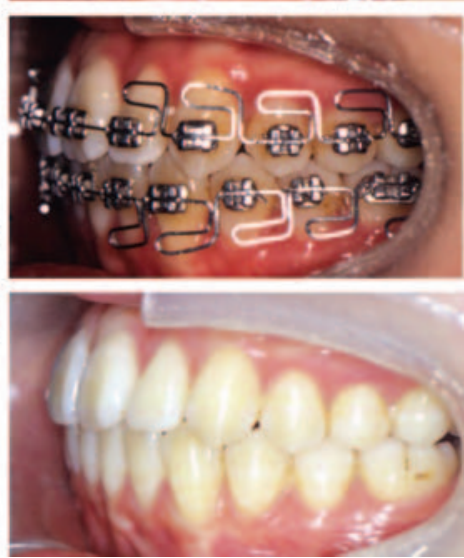

Fig. 10: Sequence of orthodontic treatment 
We evaluated her movements, and found that her right condyle did not move in protrusion/retrusion, mediotrusion right/left, and open/close movement (Fig. 5). In masticatory movement, there was limitation in the movement of EMPI, and both condyles showed compression when moving from RP to ICP, and RP in the clenching position (Fig. 6). Magnetic resonance imaging (MRI) showed that her right condyle did not move at all and the left-side disk was anteriorly displaced with reduction (Fig. 7). BruxChecker [12], a device developed in our department, was used to record the occlusal contact pattern during sleep for two nights. This showed that only a
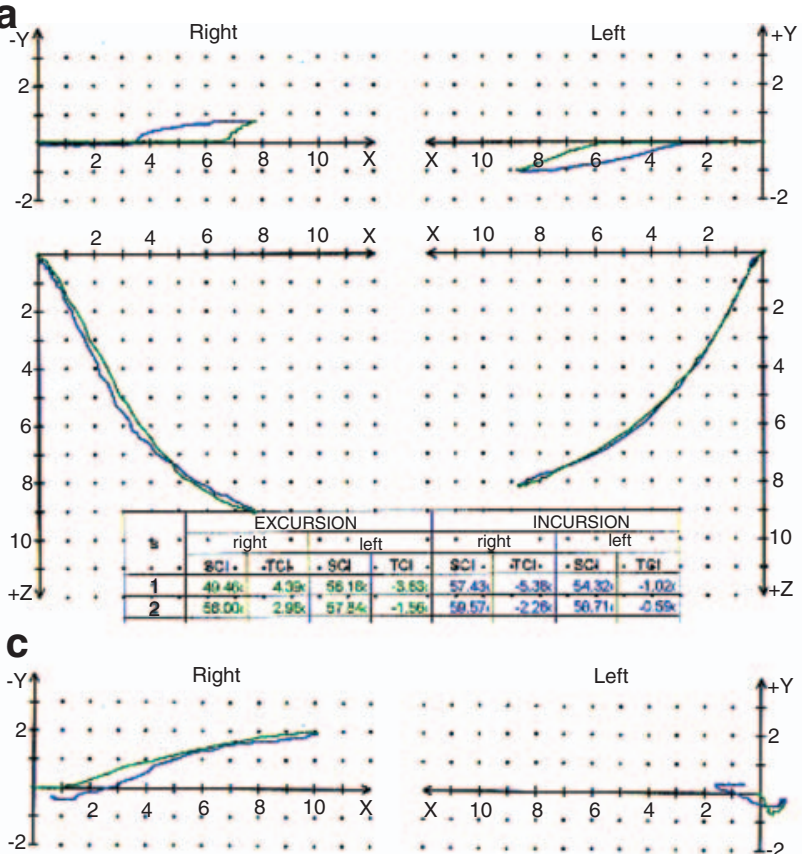

c

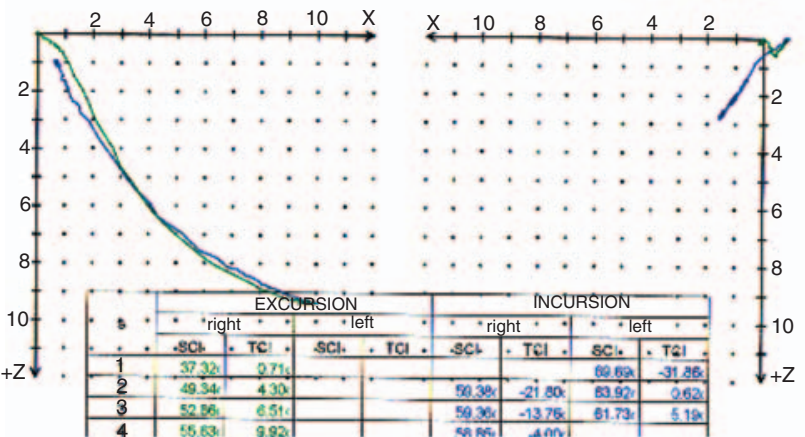

e
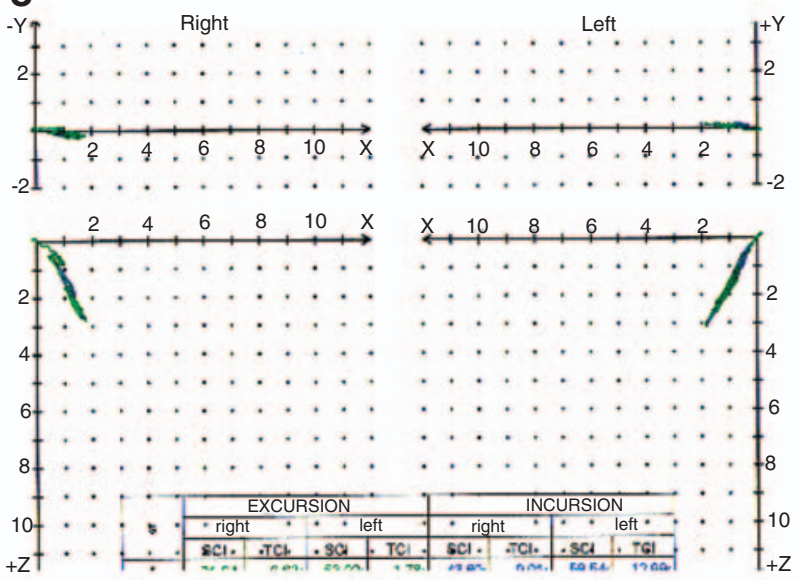

b
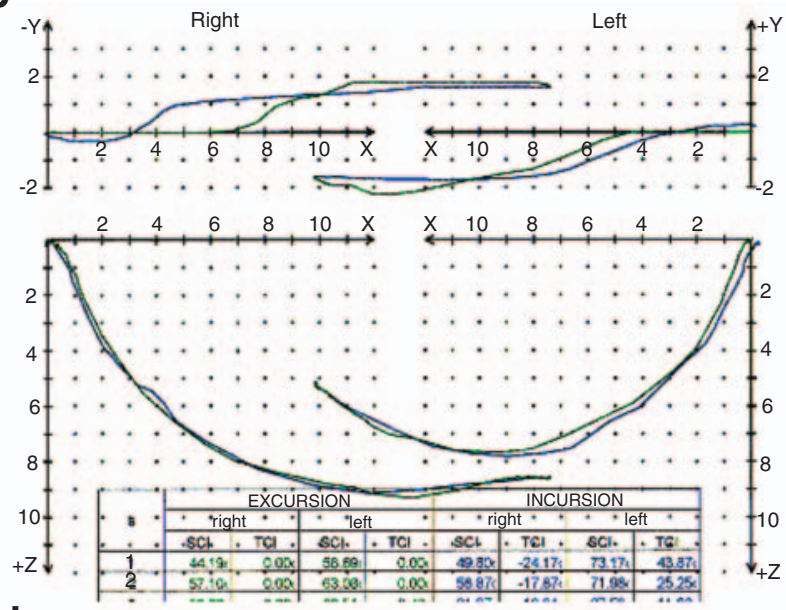

d
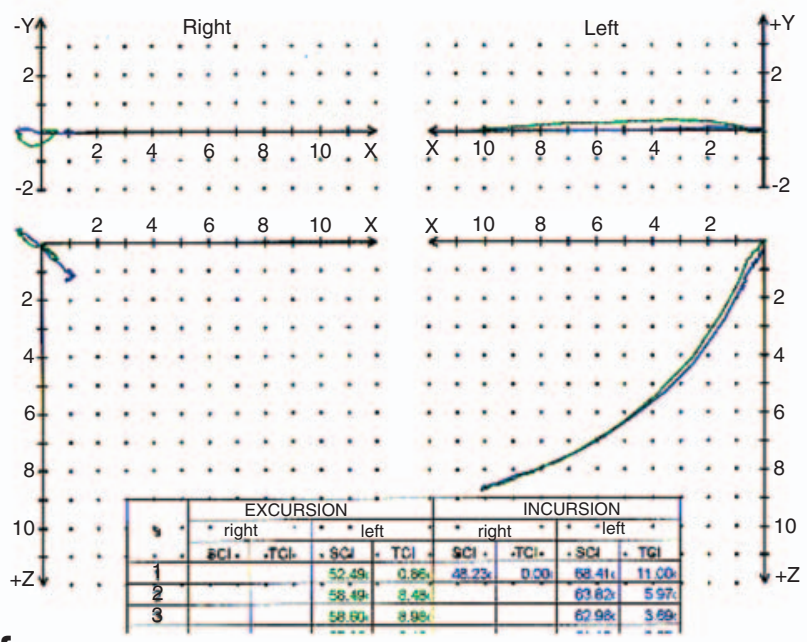

$f$
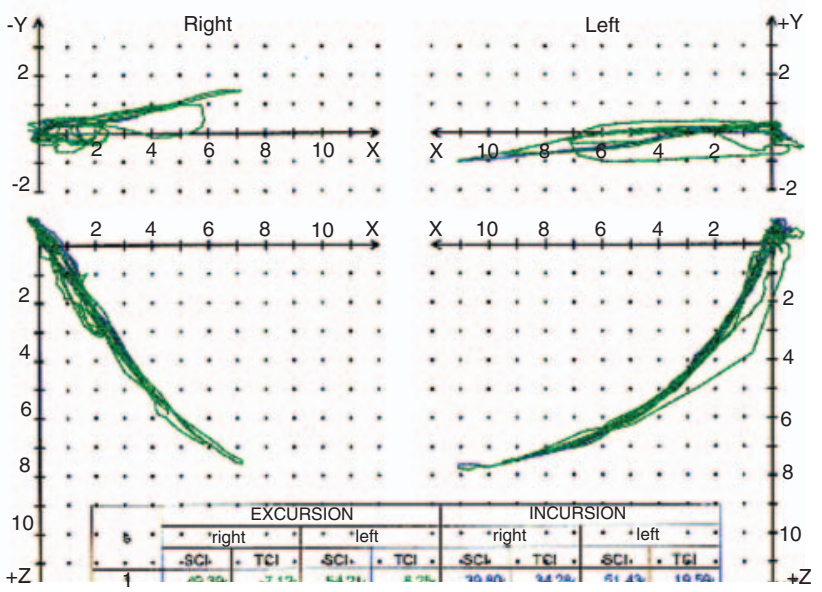

Fig. 11: Condylar movements using condylography under orthodontic treatment. (a) Protrusion/retrusion, (b) open/close, (c) mediotrusion/right, (d) mediotrusion/left, (e) bruxism movement, (f) mastication 
premolar and molar areas came into contact without canine guidance (Fig. 8).

\section{Treatment objectives}

The patient was diagnosed as skeletal Class II and dental Class I malocclusion with TMD. The treatment objectives included reconstructing the occlusal plane, establishing occlusal support, repositioning the mandible to eliminate the compression of the condyles, and achieving adequate occlusion. Therefore, it was planned to install 0.018 standard edgewise appliance with MOAW $(0.016 \times 0.022$ inch, Elgiloy wire $)$ and MEAW $(0.016 \times 0.022$ inch, Elgiloy wire $)$ [8] following extraction of lower third molars and upper second molars to reconstruct the occlusal plane and upright the posterior teeth (Fig. 9).

\section{Treatment alternatives}

Several treatment methods for correcting Class II malocclusion have been reported, including removal of the permanent tooth, especially in premolar and orthognathic surgery $[2,4,7$, 14]. These methods were effective for reducing crowding and dento-alveolar protrusion. However, in this case, providing stable occlusal support and harmonized occlusal guidance with TMJ function were the most important treatment objectives required to reposition the mandible, as the patient's mandible was retruded. To achieve this, premolar extraction should be avoided as much as possible because of loose posterior occlusal support and too much retraction of the anterior segment, which make it difficult to reposition the mandible. In addition, all the buccal teeth must be uprighted to eliminate the anterior component of occlusal forces.

Therefore, the treatment plan of the present case consisted of uprighting the buccal segment after extracting lower third and upper second molars and using modified offset archwire for uprighting molars followed by multi-loop edgewise archwire for uprighting premolars and anterior teeth. These sequential uprighting processes would reposition the mandible as well as create spaces for the elimination of tooth crowding.

\section{Treatment progress}

The initial wire MOAW was placed to upright posterior teeth by utilizing vertical elastics (3/16 inch, $6 \mathrm{oz})$ in the anterior part. After uprighting the posterior teeth, MEAW was placed to upright the premolars (Fig. 10). Six months later, the closed lock of her TMJ was relieved and she could open her mouth widely. This was because the interferences were eliminated and the mandible was repositioned by increasing vertical dimension. After leveling the lower anterior teeth, MEAW was again placed to flatten the upper occlusal plane and to achieve canine and molar Class I relationship. At this point, condylography was used to evaluate the mobility of the TMJ for functional analysis (Fig. 11). This showed that her mandible now translated without limitation and that there was a condylar deviation to the left in the transversal (Y) dimension. Because a normal occlusion was obtained in 21 months, all brackets and bands were removed to start the retention (Fig. 10).

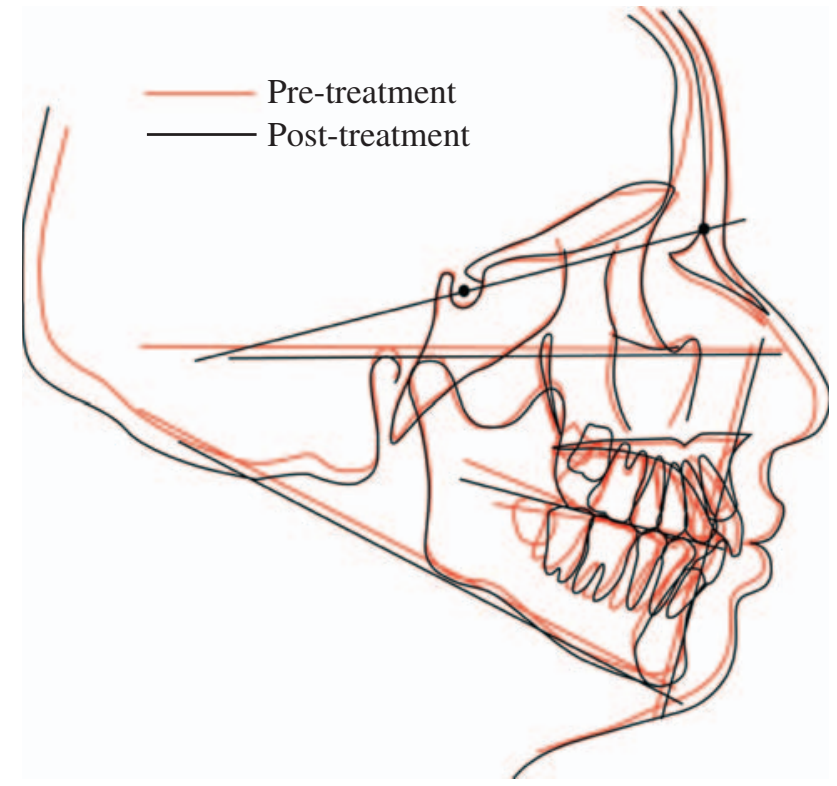

Fig. 12: Superimposition of pre- and post-treatment cephalogram tracings

\section{Treatment results}

The treatment improved esthetics and changed mandibular function. The dental arches were well aligned. Normal overjet $(2 \mathrm{~mm})$ and overbite $(2 \mathrm{~mm})$ were achieved, and Class I molar and canine relationship were established. A panoramic radiograph confirmed that no root resorption had occurred (Figs. 1-4). Superimposition of the cephalometric tracings before and after treatment showed that the occlusal plane had flattened by the end of treatment and that the mandible had adapted forward (Fig. 12). Interestingly, border condylar movement showed a decreasing amount of deviation compared with the tracing during treatment (Fig. 13). In EMPI, both condyles showed no compression when comparing RP to ICP and RP to force-bite position (Fig. 6). BruxChecker showed that canine dominance guidance was achieved (Fig. 8). The follow-up observation at 27 months after the end of the treatment showed little or no back-slide to the original occlusion. The TMJ function had no disturbances (Fig. 14). MRI showed that the relationship between the disk and condyles had recovered. Her right condyle could freely move, and the left-side disk showed anterior disk displacement with reduction (Fig. 15). The upper right third molar had started to erupt.

\section{Discussion}

The number of patients with TMD symptoms has been increasing recently. There are many ways to approach these symptoms. Owen [13] reported that the majority of orthodontic patients during treatment with TMD showed a posteriorly displaced condyle. To successfully treat these patients, it is important to reposition the displaced mandible by reconstructing the occlusion. Artun et al. [1] stated that an apparent association exists between joint sounds and posterior displacement of the condyles. In orthodontic treatment of these 
a
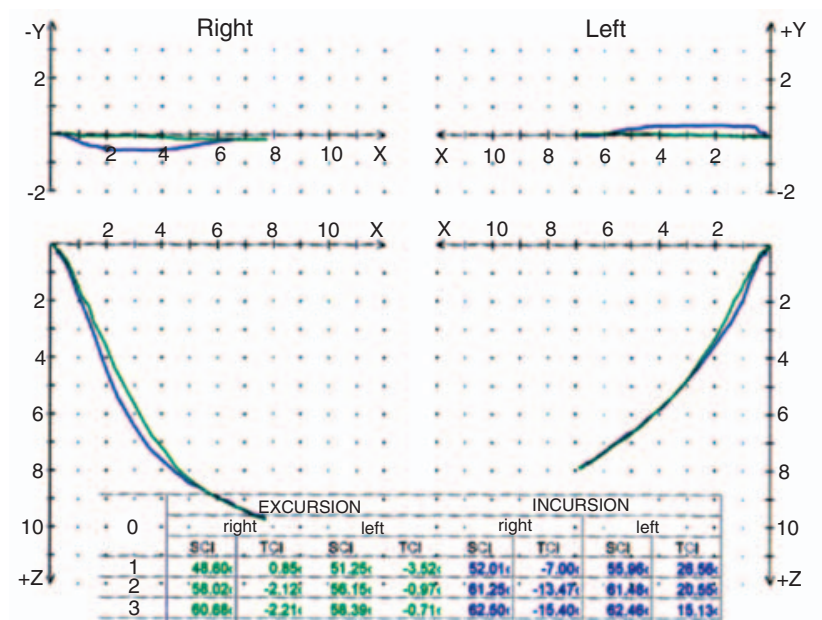

C
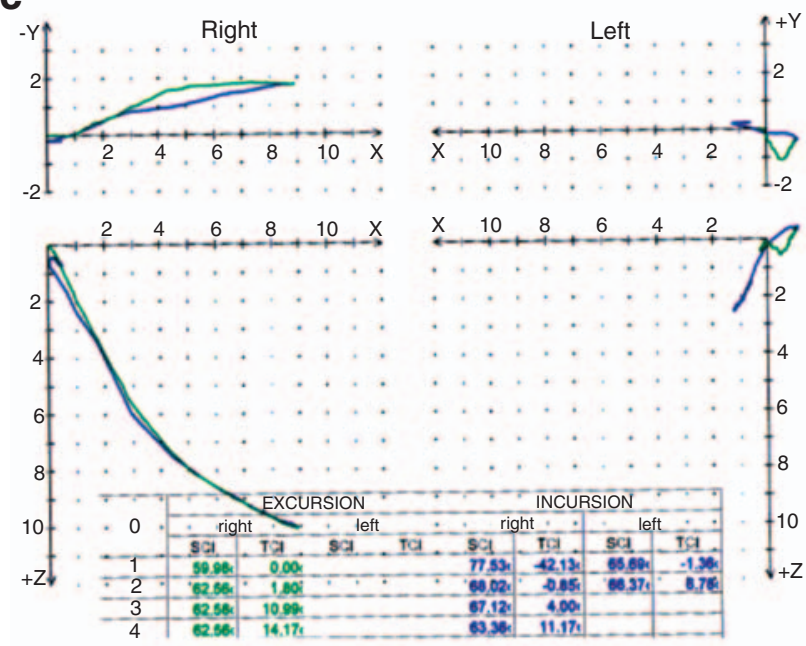

e
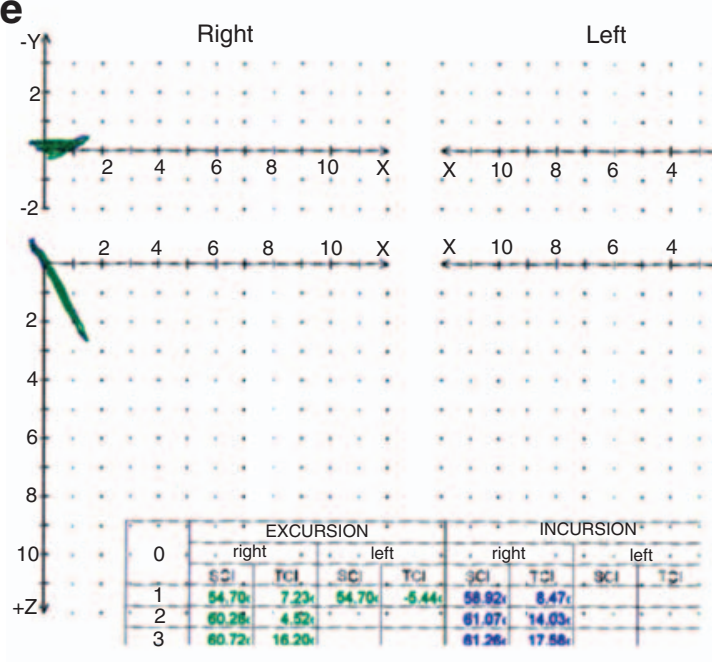

b
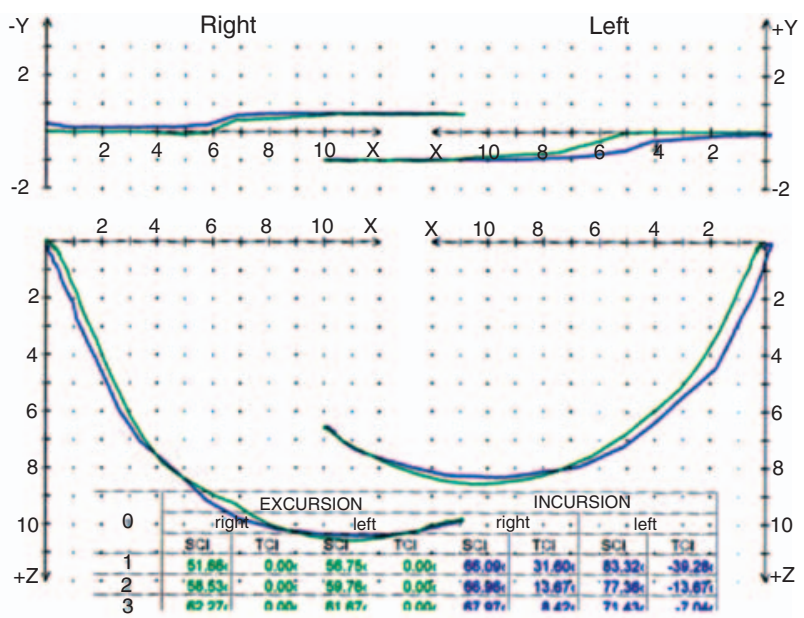

d
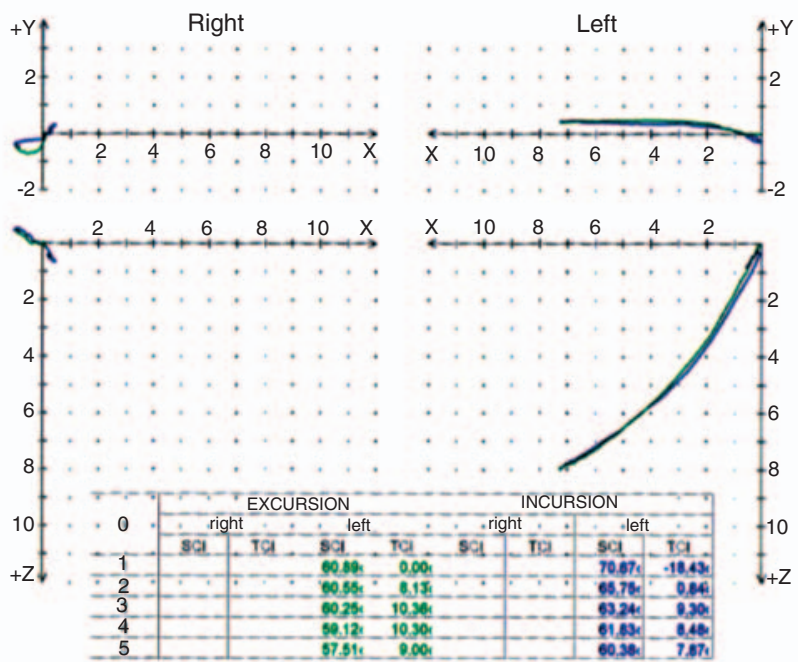

$\mathbf{f}$
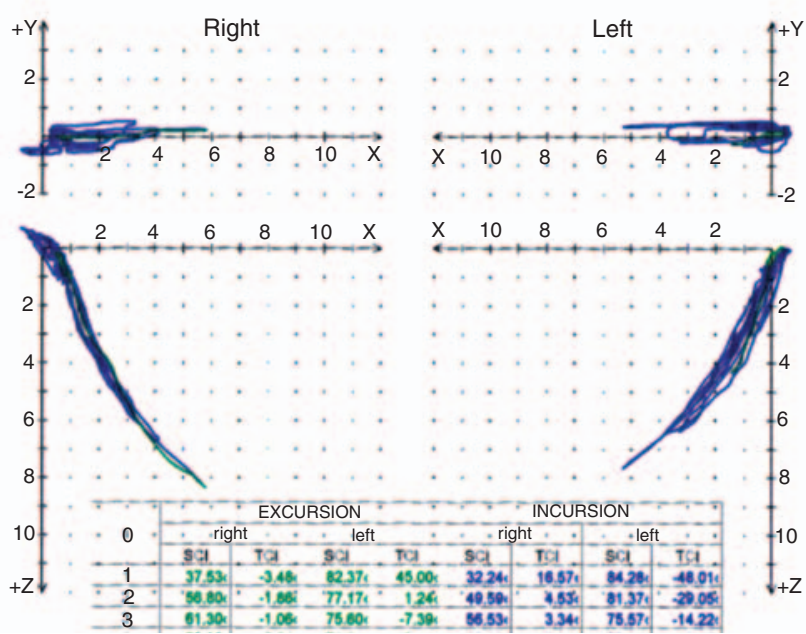

Fig, 13: Condylar movements using condylography after orthodontic treatment. (a) Protrusion/retrusion, (b) open/close, (c) mediotrusion/right, (d) mediotrusion/left, (e) bruxism movement, (f) mastication

patients, repositioning of the displaced mandible through the reconstruction of occlusion is prime importance to obtain successful outcome.
This type of approach offers to correct possible Class II skeletal relation and concomitantly improve dysfunction problems without premolar extraction and surgical intervention.

Orthodontic treatment of severe crowding malocclusion

1/2010 

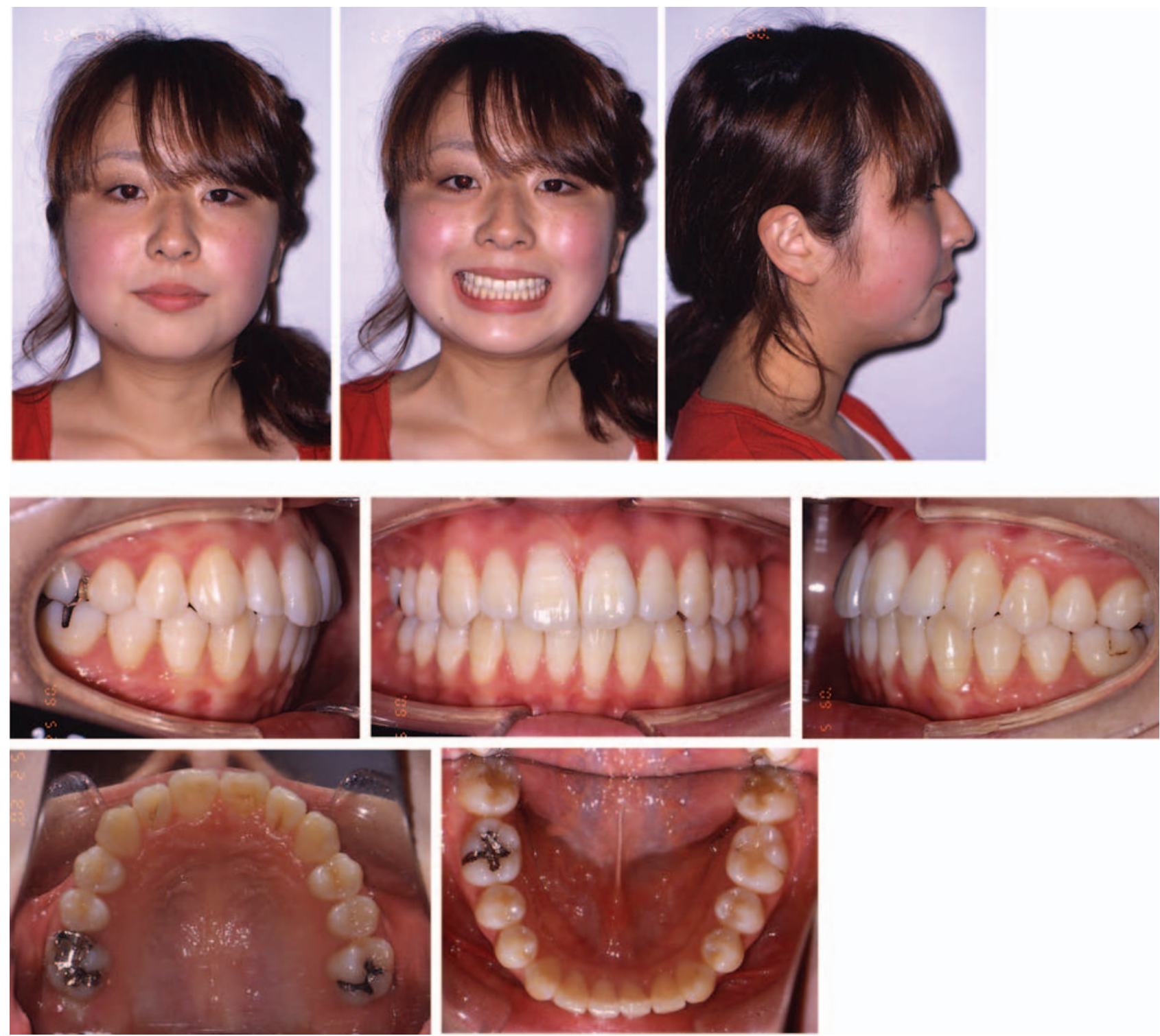

Fig. 14: The follow-up observation 27 months from the end of the treatment
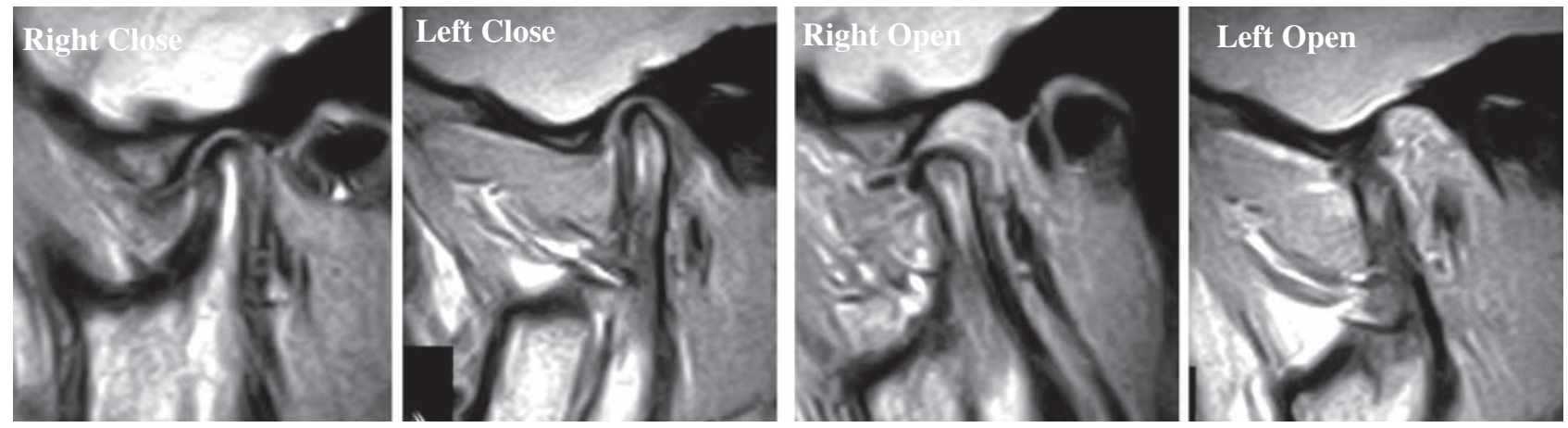

Fig. 15: MRI imaging after treatment. The relation between disk and condyle has been improving

Correction of mandibular displacement in malocclusion with TMD is the first priority in the process of the orthodontic treatment of malocclusion.
Condylographic evaluation before orthodontic treatment showed extremely limited condylar movement, which indicated a closed-lock situation of the TMJ due to disunion of 

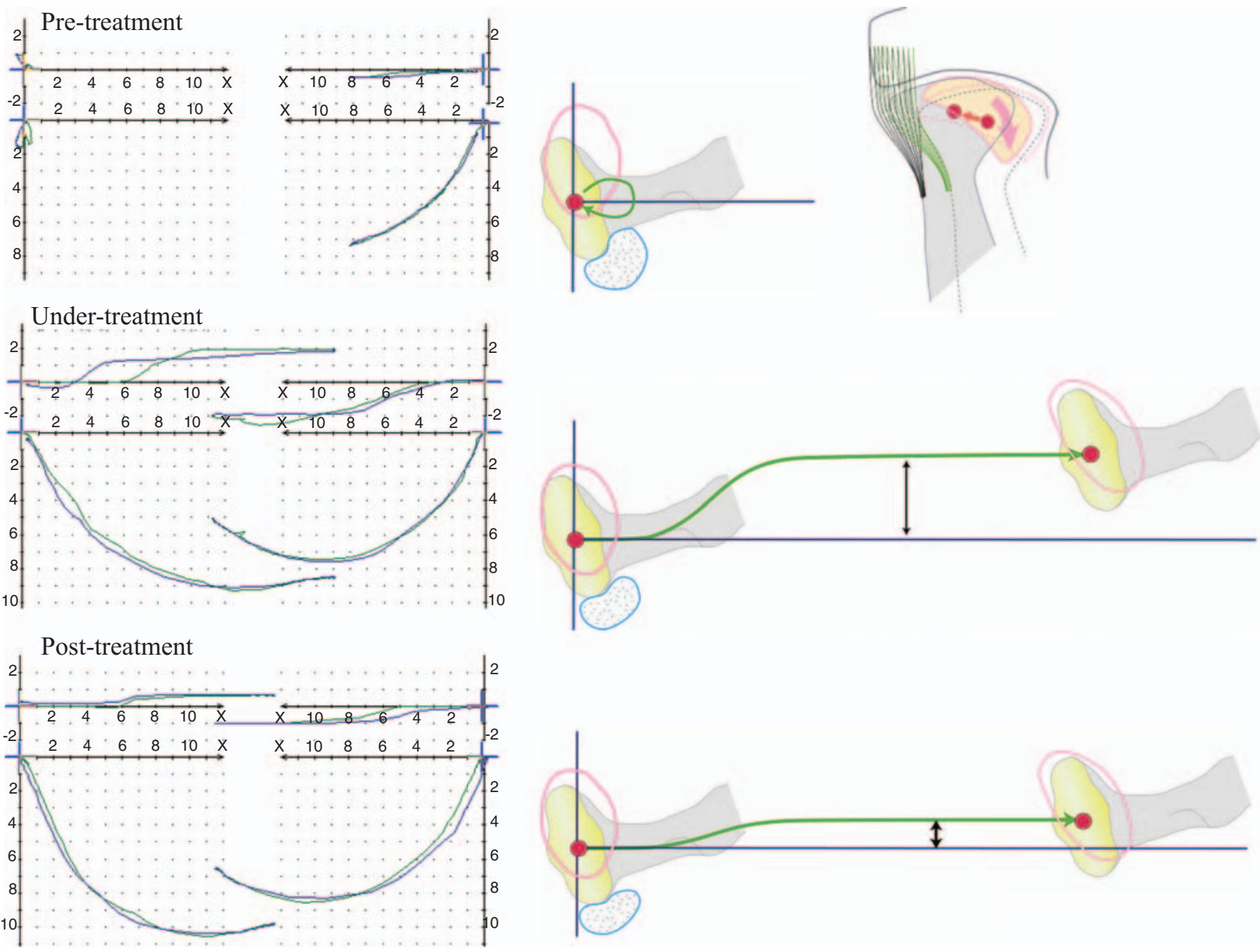

Fig, 16: Alteration of the condylar movement during orthodontic treatment. In the pre-treatment situation of TMJ, the condyle was displaced not only distally but also transversally (to the right in this case) due to her occlusion. This caused articular disk displacement and caught the condyle by lateral ligament (closed lock). Gradually changing the occlusion under treatment, altered the condyle-disk assembly providing possibility to move medially, and this caused lateral shift ( $\Delta \mathrm{Y}$ shift) of the condyle. Once the condyle-disk relation improved, the TMJ situation became better, thus condylar movement after orthodontic treatment showed decreasing $\Delta \mathrm{Y}$ shift

disk-condyle assembly caused by mandibular displacement. The closed lock of TMJ was relieved during orthodontic treatment at the completion stage of posterior segment uprighting, indicating that increasing the occlusal dental height and obtaining adequate occlusal support contributed to mandibular reposition. In this stage, condylographic tracing showed that approximately $1 \mathrm{~mm}$ lateral deviation occurred in open/close mandibular movement, indicating that her condyle was displaced laterally (to the right side) (Fig. 16). Orthodontic alterations of the biting situation improved the interrelation of the disk-condyle assembly, and the condyle obtained the ability to move medially as well as to improve disk-condyle relation. This results in lateral shift ( $\Delta \mathrm{Y}$ shift $)$ in condylographic tracing. Our previous investigation showed that the $\Delta \mathrm{Y}$ shift of the condyle is closely related with condylar deviation and direction of disk displacement [19]. After orthodontic treatment, condylar movement showed decreasing $\Delta \mathrm{Y}$ shift, which indicates a continuous improvement of diskcondylar relation.

Elimination of tooth crowding is still a frustrating topic in orthodontic treatment of malocclusion. Previously, many clinicians tried to calculate quantitatively the available space, required space and total discrepancy. Enlargement of dental arch and uprighting the inclined tooth axis provided great amounts of space which are available for eliminating crowding. Furthermore, we should consider repositioning the mandible to eliminate crowding. If the mandible is repositioned $2-3 \mathrm{~mm}$ forward, this amount of antero-posterior shift changes the occlusal relation, avoiding extraction due to upper molar distalization to correct Class II molar relation.

On the basis of these considerations, in the treatment of present case, we elected to extract the upper second molars and lower third molar. The treatment result showed one of the ways to successfully approach patients who have dysfunction of TMJ. As to treatment by extracting permanent second molars, several cases with favorable outcomes have been reported $[6,20]$.

The MEAW that was introduced by Kim is an effective tool that uprights the buccal segment of the dentition because of continuous forces with low-load deflection rate applied by multi-horizontal loops. This tool was first introduced to treat open-bite malocclusion. Since then it has evolved, and now MEAW is used to treat any type of malocclusion [8]. In the treatment of crowding malocclusion, it is necessary to upright 
posterior teeth correctly, because crowding malocclusion shows mesially inclined buccal teeth. Treatment of the present case was done by first uprighting molars with modified offset archwire followed by MEAW. This sequence of posterior uprighting was effective not only for eliminating crowding problems, but also for improving closed-lock TMJ due to increasing vertical dimension and providing stable occlusal support.

At the end of the treatment phase, TMJ function had become normal with no symptoms, and the amount of deviation of her condyle in transverse dimension had progressively decreased. During treatment, compression had been decreased, and the condyle could move smoothly with transversal deviation. After finishing orthodontic treatment, her TMJ function had become healthy with decreased transversal shift. These observations indicate that one of the key factors for successful treatment of this type of malocclusion with TMD is favorable mandibular repositioning and reconstruction of occlusion.

\section{Conclusions}

A case of crowding malocclusion with TMD was treated successfully by extracting the lower third molars and upper second molars. MOAW and MEAW were essential tools that allowed us to upright the inclined buccal teeth and to consequently establish a stable Class I occlusion. The symptoms of closed lock and malocclusion were eliminated and the patient is free from TMJ limitation and symptoms.

\section{Conflict of interest}

The authors report no conflict of interest.

\section{References}

[1] Artun J, Hollender LG, Truelove EL. Relationship between orthodontic treatment, condylar position, and internal derangement in the temporomandibular joint. Am J Orhtod Dentofacial Orthop 1992;101:48-53.

[2] Burden D, Johnston C, Kennedy D, Harradine N, Stevenson M. A cephalometric study of Class II malocclusion treated with mandibular surgery. Am J Orthod Dentofacial Orthop 2007;131:1-8.

[3] Conti PC, dos Santos CN, Kogawa EM, de Castro Ferreira Conti AC, de Araujo Cdos R. The treatment of painful temporomandibular joint clicking with oral splints: a randomized clinical trial. J Am Dent Assoc 2006;137:1108-14.
[4] Ellis CP. Category 6: Class II devision 1 malocclusion treated with extraction of permanent teeth. Am J Orthod Dentofacial Orthop 2005;128:231-40.

[5] Gonzalez-Garcia R, Rodriquez-Camopo FJ, Monje F, Sastre-Perez J, Gil-Diez Usandizaga JL. Operative versus simple arthroscpic surgery for chronic closed lock of the temporomandibular joint: a clinical study of 344 arthroscopic procedures. Int J Oral Maxillofac Surg 2008;37:790-6.

[6] Greatrex PA, Sampson WJ, Richards LC, Twelftree CC. The extraction of permanent second molars and its effect on the dentofacial complex of patients treated with the Tip-Edge appliance. Eur J Orthod 2002; 24:501-18.

[7] Janson G, Barros SE, de Freitas MR, Henriques JF, Pinzan A. Class II treatment efficiency in maxillary premolar extraction and nonextraction protocols. Am J Orthod Dentofacial Orthop 2007; 132:490-8.

[8] Kim YH. Anterior openbite and its treatment with multiloop edgewise archwire. Angle Orthod 1987;57:290-321.

[9] Kurita H, Kurashina K, Ohtsuka A. Efficacy of a mandibular manipulation technique in reducing the permanently displaced temporomandibular joint disc. J Oral Maxillofac Surg 1999;57:784-7.

[10] Murakami K, Moriya Y, Goto K, Segami N. Four-year follow-up study of temporomandibular joint arthroscopic surgery for advanced stage internal derangements. J Oral Maxillofac Surg 1996;54:285-90.

[11] Ohnuki T, Fukuda M, Nakata A, Nagai H, Takahashi T, Sasano T, Miyamoto Y. Evaluation of the position, mobility, and morphology of the disc by MRI before and after four different treatments for temporomandibular joint disorders. Dentomaxillofac Radiol 2006;35:103-9.

[12] Onodera K, Kawagoe T, Sasaguri K, Quismundo CP, Sato S. The use of a BruxChecker in the evaluation of different grinding patterns during sleep bruxism. Cranio 2006;24:292-9.

[13] Owen AH III. Unexpected temporomandibular findings during fixed appliance therapy. Am J Orhtod Dentofacial Orthop 1998;113:625-31.

[14] Pangrazio-Kulbersh V, Berger JL, Kaczynski R, Shunock M. Stability of skeletal Class II correction with 2 surgical techniques: the sagitta splint ramus osteotomy and the total mandibular subapical alveolar osteotomy. Am J Orhtod Dentofacial Orthop 2001;120:134-43.

[15] Rusanen J, Pirttiniemi P, Tervonen O, Raustia A. MRI of TMJ in patients with severe skeletal malocclusion following surgical/ orthodontic treatment. Cranio 2008;26:182-90.

[16] Schmitter M, Zahran M, Duc JM, Henschel V, Rammelsberg P. Conservative therapy in patients with anterior disc displacement without reduction using 2 common splints: a randomized clinical trial. J Oral Maxillofac Surg 2005;63:1295-303.

[17] Slavicek R. Clinical and instrumental functional analysis for diagnosis and treatment planning. Part 6. Computer-aided diagnosis and treatment planning system. J Clin Orthod 1988;22:718-29.

[18] Slavicek R. Clinical and instrumental functional analysis for diagnosis and treatment planning. Part 7. Computer-aided axiography. J Clin Orthod 1988;22:776-87.

[19] Suzuki K, Mito T, Ishizaki K, Sato S. Mandibular lateral translation during symmetric mandibular function in relation to patterns of intracapsular derangement of TMJ. J Stomato Occl Med 2009;2:16-23.

[20] Waters D, Harris EF. Cephalometric comparison of maxillary second molar extraction and nonextraction treatments in patients with Class II malocclusion. Am J Orthod Dentofacial Orthop 2001;120:608-13.

[21] Williamson EH, Sheffield JW. The treatment of internal derangement of the temporomandibular joint: a survey of 300 cases. Cranio 1987;5:120-4. 